DOI: 10.1136/annrheumdis-2019-eular.3564

\section{OP0170 USE OF THE PROVISIONAL EULAR/ACR IGG4-RD CLASSIFICATION CRITERIA IN A COHORT OF SPANISH PATIENTS}

Andreu Fernandez-Codina ${ }^{1}$, Blanca Pinilla ${ }^{2}$, lago Pinal-Fernandez ${ }^{3}$, Carlos FeijooMasso $^{4}$, Miguel Lopez-Dupla ${ }^{5}$, Eva Fonseca ${ }^{6}$, Olimpia Orozco-Galvez ${ }^{7}$, Fernando Martínez-Valle ${ }^{8}$, Registro Español de Enfermedad Relacionada con la IgG4 (REERIGG4) GEAS/SEMI. ${ }^{1}$ Western University, Rheumatology and Internal Medicine, London, Canada; ${ }^{2}$ Hospital Gregorio Maranon, Internal Medicine, Madrid, Spain; ${ }^{3}$ National Institute of Arthritis and Musculoskeletal and Skin Diseases, Muscle Disease Unit, Bethesda, United States of America; ${ }^{4}$ Consorci Sanitari Parc Tauli, Internal Medicine, Sabadell, Spain; ${ }^{5}$ Hospital Joan XXIII, Internal Medicine, Tarragona, Spain; ${ }^{6}$ Hospital de Cabuenes, Gijon, Spain; ${ }^{7}$ Hospital Universitari Vall d'Hebron, Internal Medicine, Barcelona, Spain; ${ }^{7}$ Hospital Universitari Vall d'Hebron, Internal Medicine, Barcelona, Spain

Background: The ACR/EULAR IgG4-related disease (IgG4-RD) provisional classification criteria were presented at the ACR conference in 2018. The performance of these criteria in a fully non-Asian cohort is unknown.

Objectives: To explore the performance of these provisional criteria in a cohort of Spanish patients with IgG4-RD.

Methods: Data were obtained from the Spanish IgG4-RD registry (REERIgG4) from October 2013 to December 2018, including 9 centers. Patients needed to fulfill almost 1 of the available diagnostic criteria sets (pathology consensus and/or comprehensive). $\mathrm{N}$ provisional ACR/EULAR classification criteria (PAECC) were applied based on the public information disclosed at the abovementioned meeting.

Results: One-hundred patients were included. Thirty-four (34\%) were females, median age at diagnosis was 54.8 years (IQR 20.7). The ethnicity of the participants was: Caucasian $83 \%$, Hispanic $12 \%$ and North-African/MiddleEast $5 \%$. Ninety-two percent were diagnosed with a biopsy. Regarding the diagnostic criteria, $85 \%$ met consensus pathology criteria and $94 \%$ comprehensive criteria.

Fifty-one patients $(51 \%)$ had systemic lgG4-RD involving $>1$ tissue. The most commonly involved tissues were: retroperitoneum (35\%), lymph nodes (19\%), orbit pseudotumor (18\%), salivary glands (16\%) and pancreas (14\%). Forty-two patients (42\%) had elevated serum IgG4.

Seventy-one individuals $(71 \%)$ met the PAECC including entry criteria, exclusion criteria with an inclusion criteria score equal or $>19$ points. From the 29 cases that did not meet the PAECC, $9(31 \%)$ did not fulfill the first step (entry). Those patients had rarer organs involved as hypophysis, mesenterium or jaw. Eight patients $(28 \%)$ met one of the exclusion items. Two had positive antineutrophil cytoplasmic antibodies, 2 steroid resistance, 2 double-stranded antideoxyribonucleic acid antibodies, 1 other specific autoantibodies, 1 eosinophilia and fever. None of them had evidence of active connective tissue disease, vasculitis, malignancy or infection. Finally, 16 of the patients who did not meet the PAECC (55\%) had an inclusion criteria score under 19 points (median 12): 3 $(19 \%)$ did not have a biopsy, $8(50 \%)$ biopsies had partial reports, and 10 subjects $(62.5 \%)$ had normal serum IgG4 levels. Six (38\%) of them had involvement limited to the head and neck and $3(19 \%)$ had retroperitoneal or aortic involvement.

Conclusion: Seventy-one percent of the Spanish patients participating in the REERIgG4 met the 2018 PAECC, while all of them met almost one of the previous diagnostic criteria. Populations with non-Asian ancestry might get lower scores, as they would make less points in significant domains (serum IgG4, pancreatic-biliary) or have presentations that may grant lower scores or exclusion. Enforcing complete pathology reports might increase the scores. Nevertheless, the new classification criteria are provisional and primarily intended for clinical trial recruitment, focusing in the most common manifestations. Therefore, the preexisting diagnostic criteria should be used for standard clinical purposes.

\section{REFERENCE:}

[1] Wallace Zs, Naden RP, Choi H. The 2018 ACR/EULAR Classification Criteria for igG4- Related Disease. Submitted 2018.

Disclosure of Interests: None declared

DOI: 10.1136/annrheumdis-2019-eular.3751
THURSDAY, 13 JUNE 2019

\section{From child to adult care - breaking down the barriers of transition}

\section{OP0171-PARE THE SWEDISH YOUNG RHEUMATICS REPORT - THE MOST URGENT MATTERS AND THE MOST PROMISING DEVELOPMENT AREAS FOR YOUNG PEOPLE WITH RMD'S IN SWEDEN}

Cajsa Helin Hollstrand, Kim Nordlund, Madeleine Beermann. The Swedish

National Organization for Young Rheumatics, Stockholm, Sweden

Background: In May 2017, the Swedish National Organization for Young Rheumatics (Unga Reumatiker) adopted its first political program. The program is composed by six areas and within every section we have stated what our organization want and what changes we see as necessary. To make sure we are working with the most urgent matters for our members and all of the young people with RMD's in Sweden, we wanted to do a survey, based on our political wills, amongst our members. The survey was conducted in the Autumn of 2017, with support by Pfizer, and the results were presented in the Swedish Young Rheumatics Report (Unga Reumatiker-rapporten) in April 2018.

Objectives: By conducting a survey and presenting a report, we wanted to highlight what are the largest obstacles for young people with RMD's in Sweden today. What areas need change, and what great solutions already exists? Answering these questions has been of great help for us as an organization, because we now know what matters the most to our members and what we need to focus on, but it is also of great help to others. It is for example much easier for healthcare professionals to work on fixing existing issues, now that they know what issues are of most concern for their patients. We also wanted to raise awareness about the situation for young people with RMD's in Sweden today, and inspire these people to follow their dreams.

Methods: The survey was conducted digitally and was sent out to our $1550 \mathrm{mem}$ bers and 425 people answered the survey, which consisted of 40 questions. After analyzing what stood out the most and seemed most urgent and important to the respondents, the report was composed with the most remarkable survey results, divided into four headlines; education and support, from child to adult, healthcare and treatment, and sex and family planning. We created www.ungareumatikerrapporten.se where the results are presented, and also personalized by four members telling their stories and sharing their dreams. As another part of the report, we also developed a new tool called the Dream Scale (Drömskalan). It is our response to the standard pain scale, VAS, and it is a tool meant to help inspire our members to dare to follow their dreams.

Results: We launched the report the $10^{\text {th }}$ of April with the campaign hashtag \#wearenotourdisease (\#viärintevårsjukdom). We wanted to make sure to focus on joy of life and dreams to inspire our members, while at the same time highlight some problematic areas that needs to be adjusted. With the hashtag, we also wanted to create a sense of community, and invite people to share their own stories and dreams. We published the results and shared the videos from the report website on our social media for two weeks, including popular takeovers, and got a lot of attention. We published a debate article in Dagens Medicin, Sweden's leading health care newspaper, about how it is time for a focus shift within the healthcare system. And we have sent out printed copies of the report to all clinics in Sweden, and have also lectured and keep on lecturing about the report and our work at clinics all over Sweden.

Conclusion: There is still a lot to do and a lot of changes still have to be made if all young rheumatics shall be able to experience joy of life and fulfill their dreams but the report helped us take a giant step in the right direction. We have raised awareness about what problems young people with RMD's in Sweden face on a daily basis. We know what the most urgent matters are and also what solutions we need to push for when working and talking with politicians and other decision makers. And we have been able to shift the conversation and the focus from just talking about what's bad, to talking about joy of life, hopes and dreams. We have empowered our members and others, telling them to share their own stories and dare to pursue their dreams. Having a rheumatic disease should never prevent you from living your life to the fullest!

REFERENCE:

[1] www.ungareumatikerrapporten.se

Disclosure of Interests: None declared DOI: 10.1136/annrheumdis-2019-eular.7117 